\section{6 OPEN ACCESS}

ORIGINAL ARTICLE

\title{
Long-term natural history of chronic obstructive pulmonary disease: severe exacerbations and mortality
}

\author{
Samy Suissa, ${ }^{1,2}$ Sophie Dell'Aniello, ${ }^{1}$ Pierre Ernst ${ }^{1,3}$
}

\begin{abstract}
${ }^{1}$ Center for Clinical Epidemiology, Lady Davis Institute, Jewish General Hospital, Montreal, Canada ${ }^{2}$ Department of Epidemiology and Biostatistics, and Department of Medicine, McGill University, Montreal, Canada ${ }^{3}$ Pulmonary Division, Jewish General Hospital, McGill University, Montreal, Canada
\end{abstract}

\section{Correspondence to \\ Professor Samy Suissa, Centre for Clinical Epidemiology, Jewish General Hospital, 3755 Cote Ste-Catherine, Montreal, Québec, Canada H3T 1E2; samy.suissa@mcgill.ca}

Received 15 December 2011 Accepted 30 April 2012 Published Online First 8 June 2012

\begin{abstract}
Background The long-term natural history of chronic obstructive pulmonary disease (COPD) in terms of successive severe exacerbations and mortality is unknown.
\end{abstract}

Methods The authors formed an inception cohort of patients from their first ever hospitalisation for COPD during 1990-2005, using the healthcare databases from the province of Quebec, Canada. Patients were followed until death or 31 March 2007, and all COPD hospitalisations occurring during follow-up were identified. The hazard functions of successive hospitalised COPD exacerbations and all-cause mortality over time were estimated, and HRs adjusted for age, sex, calendar time and comorbidity.

Results The cohort included 73106 patients hospitalised for the first time for COPD, of whom 50580 died during the 17 -year follow-up, with $50 \%$ and $75 \%$ mortality at 3.6 and 7.7 years respectively. The median time from the first to the second hospitalised exacerbation was around 5 years and decreased to $<4$ months from the 9 th to the 10th. The risk of the subsequent severe exacerbation was increased threefold after the second severe exacerbation and 24-fold after the 10th, relative to the first. Mortality after a severe exacerbation peaked to 40 deaths per 10000 per day in the first week after admission, dropping gradually to 5 after 3 months. Conclusions The course of COPD involves a rapid decline in health status after the second severe exacerbation and high mortality in the weeks following every severe exacerbation. Two strategic targets for COPD management should include delaying the second severe exacerbation and improving treatment of severe exacerbations to reduce their excessive early mortality.

\section{INTRODUCTION}

Chronic obstructive pulmonary disease (COPD), characterised by progressive, generally irreversible, airflow limitation associated with an abnormal inflammatory response of the lungs, has been increasing in prevalence, affecting over 12 million people in the USA alone, where it has become the third leading cause of death. ${ }^{1-3}$ While the disease course involves a slow progressive deterioration in airflow, it is punctuated by exacerbations, many of which are serious, requiring hospitalisation and associated with higher mortality and elevated costs. ${ }^{4-6}$

The progressive deterioration in COPD has traditionally been illustrated by the Fletcher-Peto curves that suggest a smooth continuous acceler-

\section{Key messages}

What is the key question?

- What is the long-term natural history of patients hospitalised for the first time for chronic obstructive pulmonary disease (COPD) in terms of the expected frequency and timing of subsequent severe COPD exacerbations and mortality?

\section{What is the bottom line?}

- We can expect a rapid decline in health status after the second severe exacerbation and high mortality in the weeks following every severe exacerbation.

\section{Why read on?}

- This suggests two strategic targets for COPD management, namely delaying the second severe exacerbation and intensifying inpatient treatment of COPD exacerbations to prevent excessive early mortality.

ated decay in lung function over time. ${ }^{7}$ Such a gradual decay in forced expiratory volume in $1 \mathrm{~s}$ $\left(\mathrm{FEV}_{1}\right)$ inherently implies that exacerbations interspersed within the course of disease do not necessarily alter this natural history. Yet, recent studies report an association between exacerbations and a greater decline in lung function. ${ }^{8}$ Moreover, increasing exacerbation frequency has been associated with higher mortality, ${ }^{5}$ while exacerbations appear to cluster in time, ${ }^{9}$ and a history of exacerbations is the single best predictor of future exacerbations. ${ }^{10}$ Thus, rather than the smooth gradual decay suggested by the Fletcher-Peto curves, these findings evoke more a stepwise component to the deterioration in COPD over time. ${ }^{11}{ }^{12}$ Such a hypothesis, however, is uncertain as all natural history studies have been based on prevalent cohorts where disease duration is not considered and the first COPD exacerbation under study is seldom the first in the patient's course of disease. As a result, the natural course of COPD over the long term remains largely unknown, particularly as it relates to its duration, the impact of successive exacerbations and the effect on mortality, two major outcomes of this disease.

We use a large population-based inception cohort of patients from their first severe COPD 
exacerbation to describe the long-term profile of severe COPD exacerbations over time and their association with mortality.

\section{Methods}

\section{Data source}

We used the computerised databases of the Régie de l'assurance maladie du Québec (RAMQ) from the health insurance program of the province of Québec, Canada for its 7 million residents. The databases include information on demographics and all medical services rendered, including hospitalisations in acute care hospitals. For people aged 65 years or older, social welfare recipients and, since 1996, residents who choose to join the provincial drug plan, the prescription drugs database includes all dispensed outpatient prescription medications. The RAMO Databases, linked by a unique health insurance number, have been used previously to conduct several epidemiological studies, including studies in COPD. ${ }^{13-18}$

\section{Study cohort}

We first identified all subjects who, during 1990-2005, were dispensed at least one prescription for respiratory medications including $ß$ agonists, theophylline, ipratropium bromide, tiotropium, inhaled corticosteroid, nedocromil, ketotifen, cromolyn or anti-leukotriene. After the first prescription for a respiratory medication, we formed the cohort of all patients with a first severe COPD exacerbation, defined as their first hospitalisation with a primary discharge diagnosis of COPD (International Classification of Diseases ninth revision (ICD-9) codes 490-492 and 496, ICD-10 codes J40-J44). To increase the likelihood of a correct diagnosis, we excluded subjects aged $<55$ years at the time of this first hospitalisation and those with a prior asthma hospitalisation. Cohort members were followed from this first hospitalisation for COPD until death or 31 March 2007. All severe exacerbations, defined as subsequent hospitalisations with a primary discharge diagnosis of COPD, occurring during follow-up, were identified.

\section{Data analysis}

Cohort entry was defined differently for the two study outcomes, namely severe exacerbation and mortality. To analyse the rate of a subsequent severe exacerbation, cohort entry was defined as the date of live discharge from hospital while, to study mortality, cohort entry was defined as the date of admission to account for the fact that patients were at risk of death during a COPD hospitalisation.

For the analysis of mortality, the Kaplan-Meier technique was first used to estimate the cumulative incidence function of time to death from cohort entry. To assess the effect of each successive severe exacerbation on mortality, a Cox proportional hazards model was used to estimate the hazard ratio (HR) of death as a function of the severe exacerbation sequence number occurring during follow-up time, included as a time-dependent
Figure 1 Flowchart of cohort formation. COPD, chronic obstructive pulmonary disease.

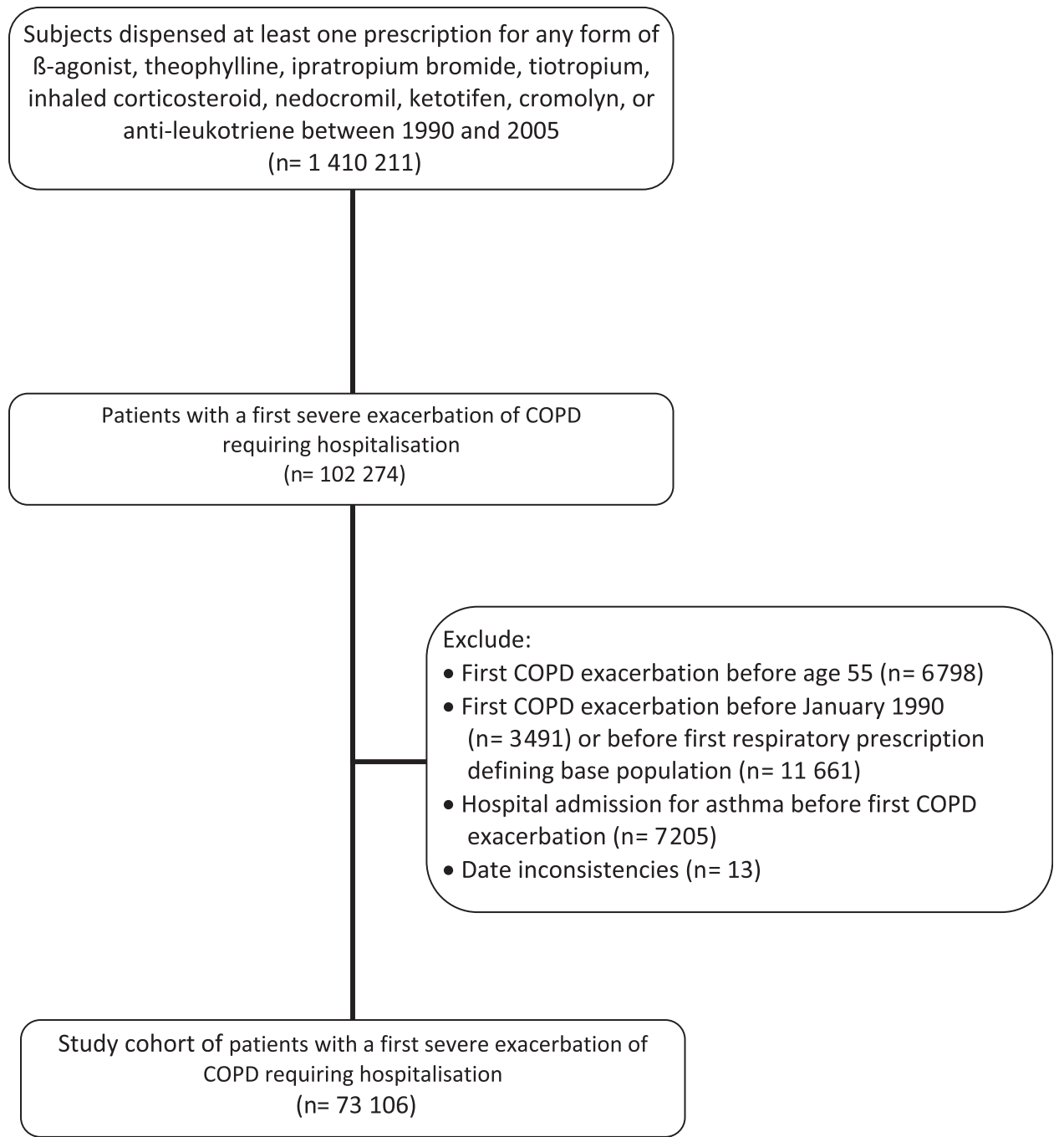


factor to consider its timing, relative to the hazard of death after the first severe exacerbation. Age in years, sex, calendar time of cohort entry (before or after the year 2000 to account for changes in patient management) and comorbidity measured at cohort entry were also included as adjustment factors for this effect. Comorbidity was measured using the modified Von Korff chronic disease score, devised specifically for healthcare databases, divided into quartiles. ${ }^{19}$ Age and sex were not included in the score to allow estimation of their independent effects. The same Cox proportional hazards model approach was also used to estimate the effect of each successive severe exacerbation on the subsequent one, with a time-dependent factor to account for the timing of each severe exacerbation over follow-up time.

The overall hazard function of the successive severe exacerbations was estimated in two steps. First, to estimate the interexacerbation times, the cohort of patients discharged alive from their first ever COPD hospitalisation was followed until the earliest of the dates of admission for the second severe COPD exacerbation, death or the end of the observation period. This follow-up to the next severe exacerbation was repeated after each severe exacerbation. The median time from each severe exacerbation to the next was estimated using the Kaplan-Meier technique modified for competing risks to account for deaths occurring before the next severe exacerbation. ${ }^{20}$ An additional approach to account for deaths was based on estimating the median time between live discharge and the date of admission for the next severe COPD exacerbation or death, whichever occurred first, using the Kaplan-Meier technique. Second, the life-table approach was used to estimate the hazard function over time of a subsequent severe exacerbation after each severe exacerbation. Thus, the hazard functions of each successive severe exacerbation were combined with the respective median inter-exacerbation times to graphically express the hazard function of successive severe exacerbations over time.

\section{RESULTS}

There were 1410211 people dispensed respiratory medications during 1990-2005, resulting in a study cohort of 73106 patients admitted for their first severe exacerbation of COPD requiring hospitalisation (figure 1). At cohort entry, the subjects had a mean age of 75 years (IOR 70-81) and 54\% were men, with the majority having received bronchodilators, corticosteroids or theophylline in the year prior to the first COPD hospitalisation (table 1), and 6.3\% having used smoking cessation medications.

During the mean follow-up of 3.6 years (range 1 day to 17 years), 33166 patients had at least one subsequent severe exacerbation requiring hospitalisation and 50580 died (baseline characteristics in table 1 ). The mean rate of severe exacerbation requiring hospitalisation was 37.8 per 100 per year, while the mortality rate was 19.2 per 100 per year. While the mean age at the initial cohort entry exacerbation was 75 years, it remained practically the same at 75 years at the time of each subsequent severe exacerbation, an effect of age-related mortality. Figure 2 shows the cumulative mortality over the 17-year follow-up period, with a median survival of 3.6 years, $75 \%$ mortality at 7.7 years and $96 \%$ mortality by 17 years.

Figure $3 \mathrm{~A}$ displays the hazard function of the time to the next severe exacerbation for the first 10 severe exacerbations after the first COPD hospitalisation. This graph illustrates three aspects of the risk. First, the median time between successive severe exacerbations decreases with every new severe exacerbation, from around 5.4 years from the first to the second to $<4$ months from the 9 th to the 10 th. However, figure $3 \mathrm{~B}$ finds a similar
Table 1 Patient characteristics at cohort entry for the entire cohort defined by the first hospitalisation for a chronic obstructive pulmonary disease (COPD) exacerbation, for those patients with subsequent COPD exacerbations and for those who died during follow-up

\begin{tabular}{|c|c|c|c|}
\hline & Entire cohort & $\begin{array}{l}\text { At least one } \\
\text { subsequent } \\
\text { exacerbation }\end{array}$ & Deaths \\
\hline Number & 73106 & 33166 & 50580 \\
\hline $\begin{array}{l}\text { Age at cohort entry } \\
\text { (years; mean } \pm S D \text { ) }\end{array}$ & $75.4 \pm 8.4$ & $73.9 \pm 7.9$ & $76.4 \pm 8.1$ \\
\hline Men $(\%)$ & 54.5 & 56.7 & 59.0 \\
\hline Cohort entry after year $2000(\%)$ & 42.5 & 32.0 & 28.2 \\
\hline \multicolumn{4}{|c|}{ Respiratory medications in the year prior to cohort entry* $(\%)$} \\
\hline Short-acting $\beta$ agonists & 80.0 & 87.1 & 81.6 \\
\hline Long-acting $\beta$ agonists & 15.5 & 14.4 & 10.1 \\
\hline Ipratropium bromide & 46.6 & 51.9 & 46.4 \\
\hline Tiotropium & 2.2 & 1.4 & 0.8 \\
\hline Inhaled corticosteroids & 59.4 & 65.9 & 58.0 \\
\hline Oral corticosteroids & 33.5 & 38.7 & 32.2 \\
\hline Theophylline & 29.2 & 37.0 & 36.1 \\
\hline Respiratory antibiotics & 60.3 & 63.0 & 61.4 \\
\hline \multicolumn{4}{|c|}{ Modified Chronic Disease Score* (\%) } \\
\hline First quartile & 24.8 & 24.7 & 25.3 \\
\hline Second quartile & 25.1 & 27.0 & 25.5 \\
\hline Third quartile & 25.1 & 25.8 & 25.2 \\
\hline Fourth quartile & 25.0 & 22.5 & 24.0 \\
\hline
\end{tabular}

${ }^{*}$ At least one dispensed prescription among the $94 \%$ of patients with available medication information in the year prior to cohort entry.

pattern, but a shorter time span between severe exacerbations and the earliest of the next severe exacerbation or death. Second, when the patient is discharged after each severe exacerbation, the risk of the next severe exacerbation peaks during the trimester following discharge, jumping by 30-40 severe exacerbations per 10000 per day, decreasing significantly thereafter to a lower baseline rate. Third, the baseline rate of a severe exacerbation increases with every new severe exacerbation, increasing from a baseline rate of around 3 per 10000 per day for the first severe exacerbation to 50 per 10000 per day for the 9 th severe exacerbation.

Table 2 quantifies these increases, showing that the rate of a subsequent severe exacerbation is three times higher after the

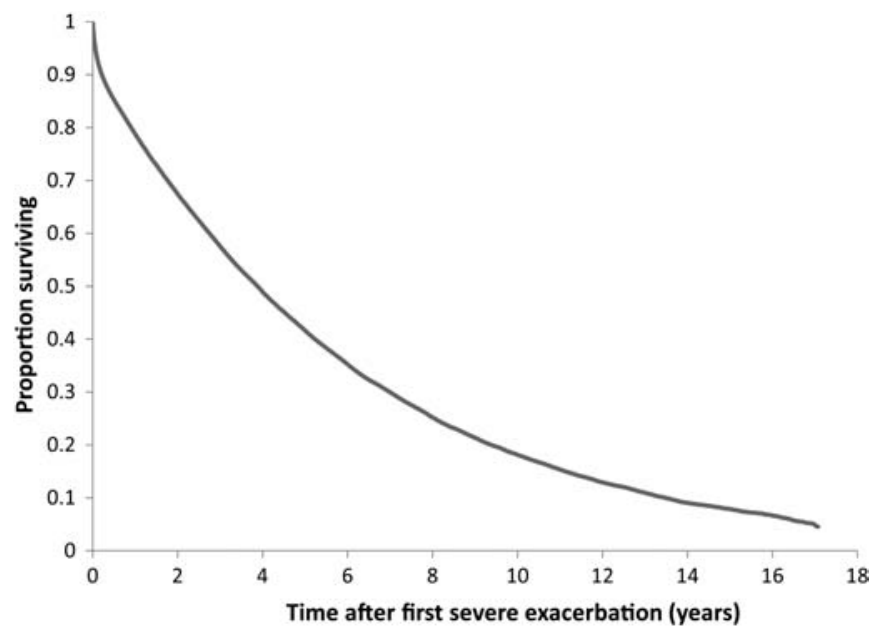

Figure 2 Kaplan-Meier survival function for the cohort of 73106 patients from the time of their first ever hospitalisation for a chronic obstructive pulmonary disease exacerbation over the 17-year follow-up period. 

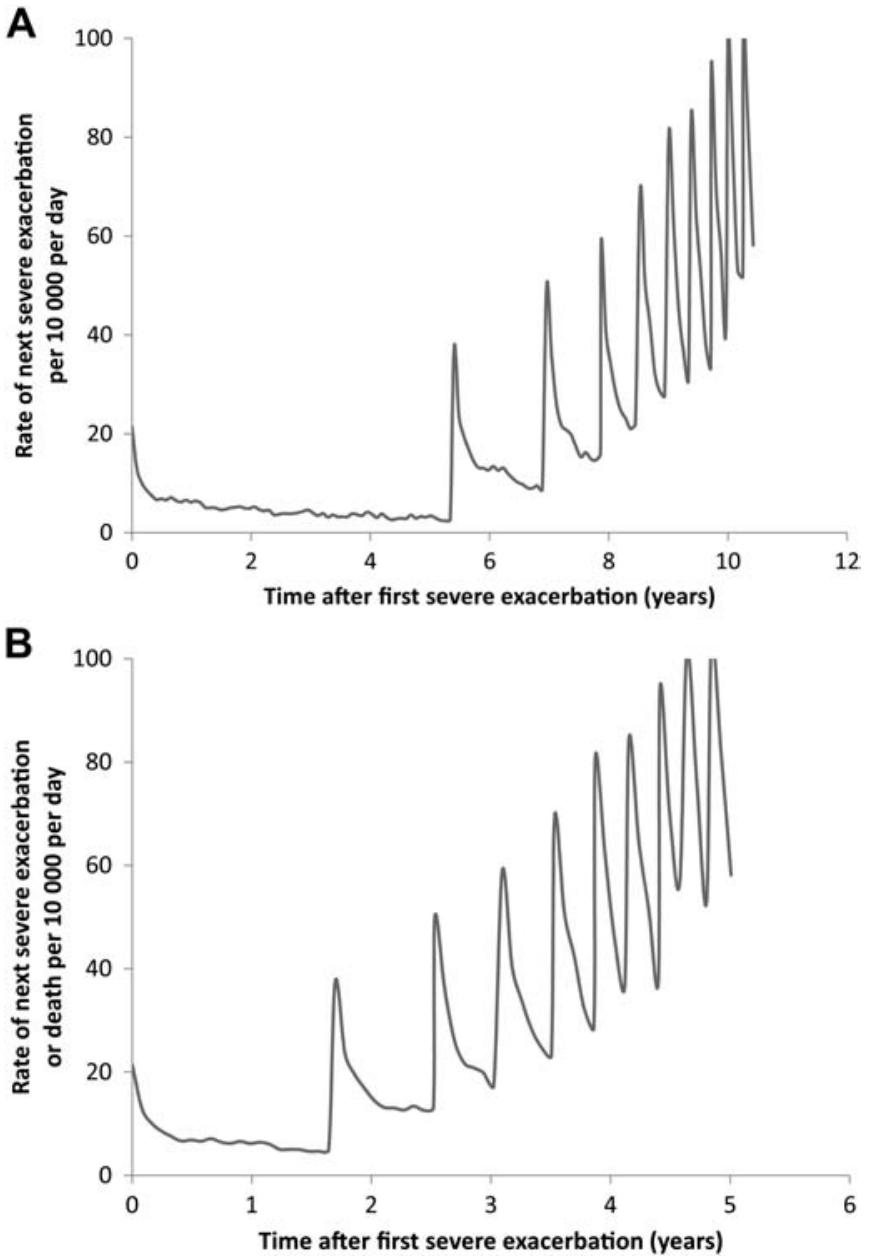

Figure 3 Hazard function of successive hospitalised chronic obstructive pulmonary disease (COPD) exacerbations (per 10000 per day) for the cohort of 73106 patients from the time of their first ever hospitalisation for a COPD exacerbation over the follow-up period, with the time between successive exacerbations estimated using: $(A)$ the median inter-exacerbation times, conditional on survival with death as a competing risk; and (B) the median inter-exacerbation times as time to the next exacerbation or death, whichever occurs first.

second than after the first and almost 25 times higher after the 10th than after the first. Table 2 also displays the rate of death occurring between successive severe exacerbations, showing that the rate of death after the second severe exacerbation is 1.9 times
Table 3 Adjusted hazard ratio (HR) of a subsequent exacerbation and of death associated with age, sex, calendar time of cohort entry and quartiles of the modified Chronic Disease Score by Cox proportional hazards model with time-dependent covariate defining the exacerbation number

\begin{tabular}{lll}
\hline & $\begin{array}{l}\text { Exacerbation } \\
\text { HR (95\% Cl) }\end{array}$ & $\begin{array}{l}\text { Death } \\
\text { HR (95\% Cl) }\end{array}$ \\
\hline Age (per 10 years) & $0.90(0.89$ to 0.91$)$ & $1.66(1.64$ to 1.68$)$ \\
Men & $1.21(1.19$ to 1.22$)$ & $1.37(1.35$ to 1.40$)$ \\
$\begin{array}{l}\text { Cohort entry after year 2000 } \\
\text { Modified Chronic Disease Score }\end{array}$ & $0.82(0.80$ to 0.83$)$ & $0.90(0.88$ to 0.92$)$ \\
$\quad$ First quartile & 1.00 (reference) & 1.00 (reference) \\
$\quad \begin{array}{l}\text { Second quartile } \\
\text { Third quartile }\end{array}$ & $1.08(1.06$ to 1.10$)$ & $1.03(1.00$ to 1.06$)$ \\
Fourth quartile & $1.10(1.08$ to 1.12$)$ & $1.15(1.12$ to 1.18$)$ \\
\hline
\end{tabular}

higher than after the first, while after the 10th it is five times higher than after the first, all after adjusting for age, sex, calendar time and comorbidity.

Table 3 shows the impact of age, sex, calendar time and the comorbidity index on the rate of a subsequent exacerbation and of death. The rate of exacerbation decreases by $10 \%$ with each additional decade of age, while the rate of death increases by $66 \%$ with each decade. Men have higher rates of exacerbation and mortality than women, while patients having their first exacerbation after the year 2000 have lower rates of subsequent exacerbations and mortality than those prior to 2000. In particular, the median time from the first to the second severe exacerbation is higher at 7.2 years in patients who enter the cohort after the year 2000 compared with 4.2 years before 2000 , while it is 7.1 years for women and 4.4 years for men, and 13.2 years for patients over the age of 75 at cohort entry versus 3.9 years for those younger than 75 . Moreover, the median time from the first to the second severe exacerbation or death is 1.9 years in patients who enter the cohort after the year 2000 versus 1.5 years before 2000, 2.1 years for women and 1.4 years for men, and 1.5 years for patients over the age of 75 at cohort entry versus 1.8 years for those younger than 75 . Patients with more comorbidity also have higher incidences of these outcomes.

Figure 4 magnifies, after each of the first 10 severe exacerbations, the first year of the hazard function of the time to the next severe exacerbation shown in figure 2 . It shows that the rate of the next severe exacerbation systematically increases after each new severe exacerbation, peaking in the month after discharge and remaining more elevated for around 3 months. It also shows that this peak rises higher with every new severe

Table 2 Crude and adjusted hazard ratio (HR) of a subsequent exacerbation and of death associated with each successive exacerbation, as a function of the time since the first exacerbation, estimated by Cox proportional hazards model with time-dependent covariate defining the exacerbation number and its timing

\begin{tabular}{|c|c|c|c|c|c|c|c|}
\hline $\begin{array}{l}\text { Exacerbation } \\
\text { sequence number }\end{array}$ & $\begin{array}{l}\text { Median time to subsequent } \\
\text { exacerbation (years) }\end{array}$ & $\begin{array}{l}\text { Number with a subsequent } \\
\text { exacerbation }\end{array}$ & Crude HR & Adjusted* HR (95\% CI) & $\begin{array}{l}\text { Number } \\
\text { of deaths }\end{array}$ & Crude HR & Adjusted $^{*}$ HR $(95 \% \mathrm{Cl})$ \\
\hline First (reference) & 5.4 & 33166 & 1.0 & 1.0 (reference) & 25953 & 1.0 & 1.0 (reference) \\
\hline Second & 1.6 & 19359 & 3.0 & $2.9(2.8$ to 2.9$)$ & 9828 & 1.8 & $1.9(1.8$ to 1.9$)$ \\
\hline Third & 0.9 & 12413 & 5.1 & $4.9(4.8$ to 5.0$)$ & 5203 & 2.4 & $2.4(2.3$ to 2.5$)$ \\
\hline Fourth & 0.7 & 8374 & 7.3 & $6.9(6.8$ to 7.1$)$ & 3078 & 2.8 & $2.9(2.8$ to 3.0$)$ \\
\hline Fifth & 0.5 & 5903 & 9.8 & 9.2 (8.9 to 9.4$)$ & 1879 & 3.0 & $3.2(3.0$ to 3.4$)$ \\
\hline Sixth & 0.4 & 4316 & 11.9 & $11.2(10.8$ to 11.5$)$ & 1207 & 3.1 & $3.3(3.1$ to 3.5$)$ \\
\hline Seventh & 0.3 & 3190 & 13.9 & $13.0(12.5$ to 13.5$)$ & 872 & 3.4 & $3.6(3.4$ to 3.9$)$ \\
\hline Eighth & 0.3 & 2404 & 16.6 & $15.2(14.6$ to 15.9$)$ & 645 & 3.9 & 4.2 (3.9 to 4.5$)$ \\
\hline Ninth & 0.3 & 1823 & 18.1 & 16.6 (15.8 to 17.4$)$ & 470 & 3.8 & $4.3(3.9$ to 4.7$)$ \\
\hline Tenth or greater & 0.2 & 1403 & 25.8 & 23.5 (22.8 to 24.2$)$ & 1445 & 4.5 & $5.2(4.9$ to 5.5$)$ \\
\hline
\end{tabular}

*Adjusted for age, sex, calendar time (cohort entry prior to 2000), and the modified Chronic Disease Score divided in quartiles with a fifth category to account for subjects with no or partia medication information in the year prior to cohort entry. 


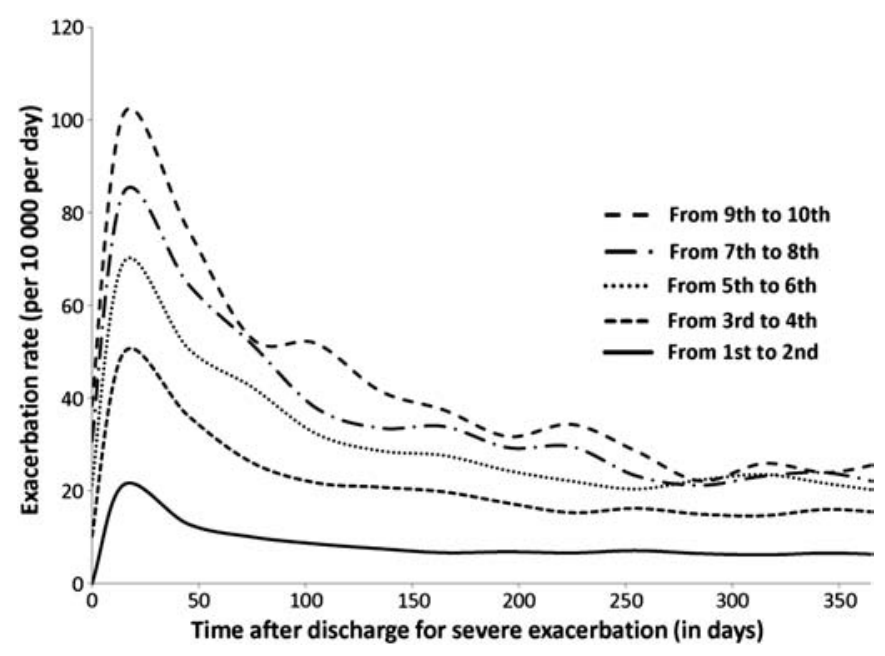

Figure 4 Hazard function of a subsequent hospitalised chronic obstructive pulmonary disease exacerbation (per 10000 per day) in the 1 -year period after discharge from the previous one.

exacerbation. Table 4 provides the corresponding crude and adjusted hazard ratios for figure 4 , showing that the increase in the risk of a subsequent severe exacerbation intensifies with every new severe exacerbation. To estimate these hazard ratios, two Cox proportional hazards models were used where at each new severe exacerbation time zero was reset at the time of discharge alive from hospital for the severe exacerbation outcome and at the time of admission for death. In essence, by resetting time zero, this model considers each new severe exacerbation as a different subject in the analysis, considering the exacerbation sequence number as a covariate.

Table 4 shows that for mortality, however, the peak does not rise much more after the third severe exacerbation. Consequently, the hazard function of mortality after a severe exacerbation was estimated from the pooled set of severe exacerbations, irrespective of the order. It shows that the daily rate of mortality after any severe exacerbation increases to a peak of 40 deaths per 10000 per day during the first week after admission for a COPD hospitalisation, dropping gradually to 5 deaths per 10000 per day by 3 months (figure 5).

\section{DISCUSSION}

Using a large population-based inception cohort of COPD patients with long-term follow-up, we showed that the occur- rence of every new severe exacerbation requiring hospitalisation worsens the course of the disease and increases the risk of a subsequent exacerbation, with patients 25 times more likely to be readmitted after their 10th COPD hospitalisation than after their first COPD hospitalisation. Also, every new severe exacerbation increases the risk of death, up to five times after their 10th compared with after their first COPD hospitalisation. This mortality peaks in the first week after admission for a COPD hospitalisation, and stabilises after 3 months, dropping eightfold.

These long-term data suggest that, after the first hospitalised exacerbation, the course of COPD is generally composed of two phases. The first is a prolonged period of stable risk until the second hospitalised exacerbation, either a 5-year interval between the first two hospitalised exacerbations, given that the patient remains alive, or more relevant to the patient, a less than 2 -year span until the next COPD hospitalisation or death. The second phase, delineated by the second hospitalised exacerbation in the patient's life, seems to significantly modify the trajectory of the disease course. From this point on, severe exacerbations increase in intensity, with eight severe exacerbations expected in a 6-year period, including 3-4 severe exacerbations in the last year alone.

We found that patients who entered the cohort after the year 2000 had a longer time to the second severe exacerbation compared with those who entered before 2000. This suggests a possible role of improvements in the management of COPD over the last two decades. Also, women are increasingly represented among patients with COPD over the time period of the study and the prognosis for women with COPD appears to be better than that of men, at least in the present study population. ${ }^{21}$ The finding that older age is associated with a longer interval between exacerbations is due to the higher mortality with age, as shown by the shorter course in older patients when defined by the combined outcome of severe exacerbation or death.

Our study also confirmed that the 2-month to 3-month period following the end of a severe exacerbation is a very high-risk period for a recurrence, and this was the case after each exacerbation. ${ }^{2} 22$ Moreover, severe exacerbations appear to recur progressively sooner after each subsequent severe exacerbation and that the mortality rate increases with every new exacerbation. Frequent exacerbations have previously been associated with higher mortality, ${ }^{5}$ and this may be independent of COPD severity as assessed by the BODE index. ${ }^{23} 24$ Moreover, our overall rates of severe exacerbations and mortality are similar to average rates reported from prevalent cohorts of patients with

Table 4 Crude and adjusted HR of a subsequent exacerbation and of mortality, as a function of the time after each successive exacerbation, estimated by Cox proportional hazards model

\begin{tabular}{|c|c|c|c|c|}
\hline \multirow[b]{2}{*}{ Exacerbation sequence number } & \multicolumn{2}{|c|}{ Exacerbation } & \multicolumn{2}{|l|}{ Mortality } \\
\hline & Crude HR & Adjusted* HR (95\% CI) & Crude HR & Adjusted* HR (95\% CI) \\
\hline First (reference) & 1.00 & 1.00 (reference) & 1.00 & 1.00 (reference) \\
\hline Second & 1.78 & $1.76(1.73$ to 1.80$)$ & 1.20 & $1.17(1.14$ to 1.20$)$ \\
\hline Third & 2.36 & 2.32 (2.27 to 2.37$)$ & 1.31 & $1.26(1.22$ to 1.30$)$ \\
\hline Fourth & 2.86 & 2.79 (2.72 to 2.86$)$ & 1.38 & $1.33(1.28$ to 1.38$)$ \\
\hline Fifth & 3.32 & 3.22 (3.13 to 3.32$)$ & 1.37 & $1.33(1.27$ to 1.39$)$ \\
\hline Sixth & 3.71 & $3.60(3.48$ to 3.71$)$ & 1.33 & $1.28(1.21$ to 1.36$)$ \\
\hline Seventh & 3.97 & 3.85 (3.71 to 3.99$)$ & 1.38 & $1.34(1.25$ to 1.43$)$ \\
\hline Eighth & 4.42 & $4.23(4.06$ to 4.41$)$ & 1.48 & $1.45(1.34$ to 1.57$)$ \\
\hline Ninth & 4.60 & $4.41(4.20$ to 4.62$)$ & 1.45 & $1.44(1.31$ to 1.58$)$ \\
\hline Tenth or greater & 5.47 & $5.21(5.07$ to 5.36$)$ & 1.49 & $1.50(1.42$ to 1.58$)$ \\
\hline
\end{tabular}

${ }^{*}$ Adjusted for age, sex, calendar time (cohort entry prior to 2000), and the modified Chronic Disease Score divided in quartiles with

a fifth category to account for subjects with no or partial medication information in the year prior to cohort entry. 
Figure 5 Daily rates of death (per 10000 per day) in the 90-day period after onset of severe chronic obstructive pulmonary disease exacerbation.

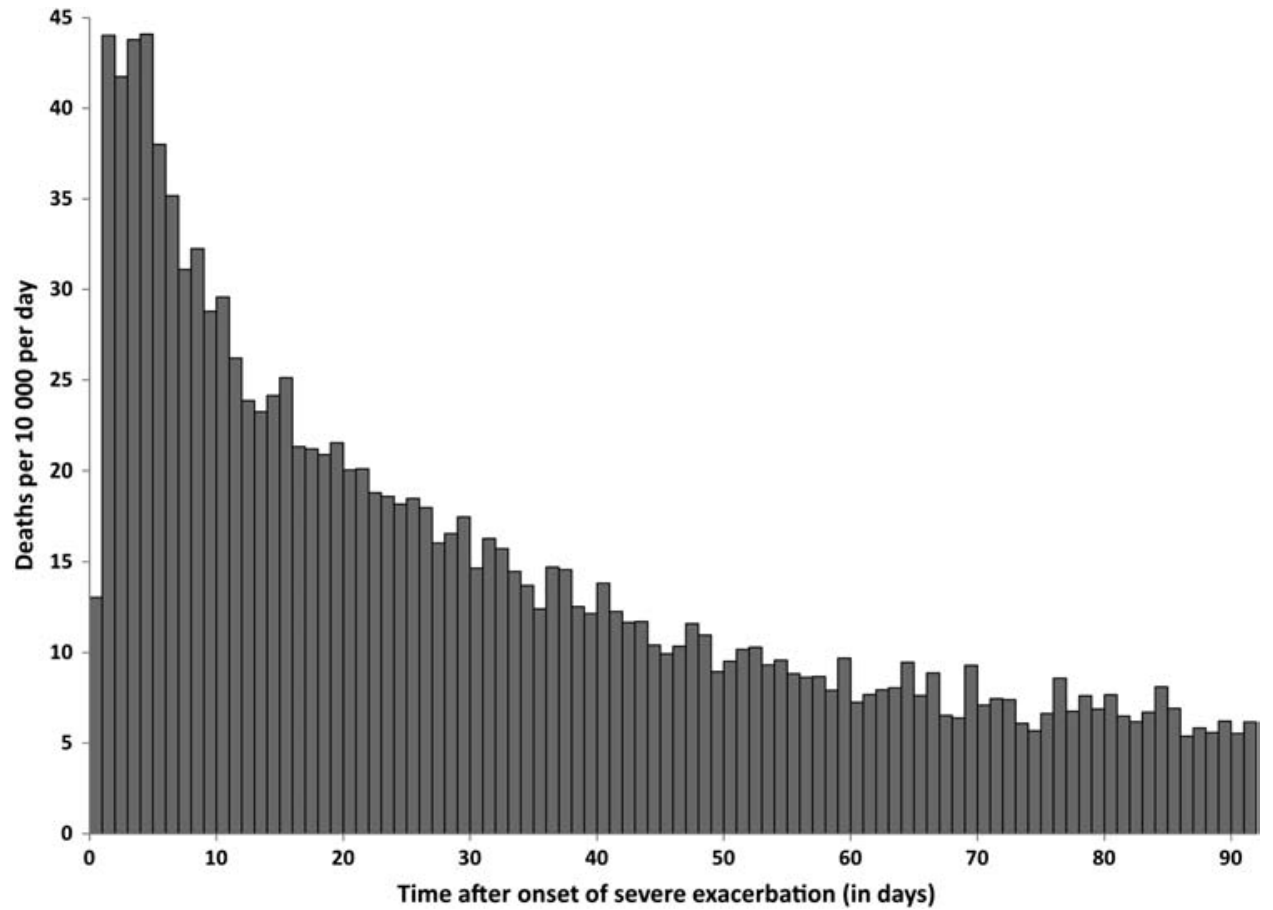

COPD. ${ }^{2526}$ We found that mortality peaks drastically during the 3 -month period following the onset of a severe exacerbation, and of the same magnitude after each severe exacerbation, including the very first one.

A strength of our study is that we studied an inception cohort of patients from their first severe COPD exacerbation. Previous epidemiological studies of this natural history were based on cohorts of patients with prevalent COPD, in which the first exacerbation under study is rarely the first ever. Thus, patients are compared at different time points in their disease course which can introduce bias in several ways. First, the frequency of exacerbations at cohort entry could reflect disease duration rather than disease severity. Indeed, patients with no exacerbations in a year could be early in their disease course while patients with multiple exacerbations could have had the disease for a long time, making it likely that part of the apparent differences in phenotypes of patients with and without frequent exacerbations is due to comparing patients at different points in the natural history of their disease. ${ }^{10}$ Second, prevalent cohorts exclude patients who die of their first or second exacerbation and do not make it into the cohort, introducing the possibility of selection bias which can exaggerate the association between the number of exacerbations and mortality.

A limitation of our study is the lack of information on the severity of symptoms, airflow limitation and exercise intolerance. Also the diagnosis of COPD cannot be verified directly either through the medical chart or records of lung function. The identification of patients with COPD was based on the primary discharge diagnosis listed for a hospitalisation, previously shown to be valid in the database used in the current study. ${ }^{27}$ To further distinguish COPD from asthma, we excluded subjects with an asthma hospitalisation prior to the first COPD hospitalisation and included only subjects whose first COPD hospitalisation occurred after the age of 55 years.

The clinical implications of these findings are important. First, mortality in the first 7 days of a hospitalisation for COPD is very high and therefore this at-risk period deserves special attention. A recent audit of COPD hospitalisations in the UK found the use of non-invasive ventilation to be suboptimal. ${ }^{28}$ Of the therapies given in this critical period, systemic corticosteroids have not shown a benefit on mortality, while to date, studies of antibiotics show promise. ${ }^{29-31}$ For those who survive, the risk of exacerbation continued to be very high for the first 3 months before settling to a baseline rate. This 3 -month period might be amenable to a reduction in risk that may be provided by transitional care programmes. ${ }^{32}$ Second, there appears to be a window of opportunity after the first hospitalisation for a COPD exacerbation that provides a significant period in which one might intervene to prevent a subsequent severe exacerbation. While several drugs have been shown to reduce the frequency or delay the onset of exacerbations, ${ }^{33-35}$ our study suggests a special focus on targeting those severe exacerbations leading to hospitalisation. This has been achieved with structured self-management plans. ${ }^{36}$ Finally, our results suggest that patients in whom severe exacerbations occur frequently and cluster together may be at a stage in their disease where end-oflife care may need to be envisaged.

In all, this natural history study has identified two strategic targets for the management of patients with COPD, namely delaying the second severe exacerbation and improving the treatment of all severe exacerbations to reduce the associated excessive early mortality. Our results support the call for increased attention to the treatment and prevention of 'lung attacks' in patients with COPD. ${ }^{37}$

Acknowledgements The authors thank the Commission d'accès à l'information du Québec for allowing access to the data and agents from the Régie de l'assurance maladie du Québec (RAMO) for sending the database.

Contributors SS acquired the data. SS, SD and PE participated in the analysis. SS and PE wrote the article. All authors had full access to the data and SS takes responsibility for the integrity of the data and the accuracy of the data analysis.

Funding This research was funded by grants from the Canadian Institutes of Health Research (ClHR), the Canadian Foundation for Innovation (CFI) and support from Boehringer-Ingelheim.

\section{Competing interests None.}

Ethics approval Ethics approval was provided by Ethics Board of the Jewish General Hospital. 
Provenance and peer review Not commissioned; externally peer reviewed.

\section{REFERENCES}

1. Rabe KF, Hurd S, Anzueto A, et al. Global strategy for the diagnosis, management, and prevention of chronic obstructive pulmonary disease: GOLD executive summary. Am J Respir Crit Care Med 2007:176:532-55.

2. Lopez AD, Shibuya K, Rao C, et al. Chronic obstructive pulmonary disease: current burden and future projections. Eur Respir J 2006:27:397-412.

3. Minino AM, Xu J, Kochanek KD. Deaths: preliminary data for 2008. National Vital Statistics Reports NCHS. 2010;59(2). http://www.cdc.gov/nchs/data/nvsr/nvsr59/ nvsr59 02.pdf

4. Wedzicha JA, Seemungal TA. COPD exacerbations: defining their cause and prevention. Lancet 2007;370:786-96.

5. Soler-Cataluna JJ, Martinez-Garcia MA, Roman SP, et al. Severe acute exacerbations and mortality in patients with chronic obstructive pulmonary disease. Thorax 2005;60:925-31.

6. Miravitlles M, Murio C, Guerrero T, et al. Pharmacoeconomic evaluation of acute exacerbations of chronic bronchitis and COPD. Chest 2002;121:1449-55.

7. Fletcher C. Peto R. The natural history of chronic air ow obstruction. Br Med J 1977;:1:1645-8.

8. Donaldson GC, Seemungal TA, Bhowmik A, et al. Relationship between exacerbation frequency and lung function decline in chronic obstructive pulmonary disease. Thorax 2002;57:847-52.

9. Hurst JR, Donaldson GC, Quint JK, et al. Temporal clustering of exacerbations in chronic obstructive pulmonary disease. Am J Respir Crit Care Med 2009:179:369-74.

10. Hurst JR, Vestbo J, Anzueto A, et al. Susceptibility to exacerbation in chronic obstructive pulmonary disease. N Engl J Med 2010;363:1128-38.

11. Hansel TT, Barnes PJ. New drugs for exacerbations of chronic obstructive pulmonary disease. Lancet 2009;374:744-55

12. Lorenz KA, Lynn J, Dy SM, et al. Evidence for improving palliative care at the end of life: a systematic review. Ann Intern Med 2008;148:147-59.

13. Garbe $\mathbf{E}$, LeLorier J, Boivin JF, et al. Inhaled and nasal glucocorticoids and the risks of ocular hypertension or open-angle glaucoma. JAMA 1997:277:722-7.

14. Garbe E, Suissa S, LeLorier J. Association of inhaled corticosteroid use with cataract extraction in elderly patients. JAMA 1998;280:539-43.

15. Ernst $\mathbf{P}$, Baltzan M, Deschenes J, et al. Low-dose inhaled and nasal corticosteroid use and the risk of cataracts. Eur Respir J 2006;27:1168-74.

16. Suissa S, Baltzan M, Kremer $\mathrm{R}$, et al. Inhaled and nasal corticosteroid use and the risk of fracture. Am J Respir Crit Care Med 2004;169:83-8.

17. Ernst $\mathbf{P}$, Gonzalez AV, Brassard $P$, et al. Inhaled corticosteroid use in chronic obstructive pulmonary disease and the risk of hospitalization for pneumonia. Am J Respir Crit Care Med 2007;176:162-6.

18. Suissa S, Kezouh A, Ernst P. Inhaled corticosteroids and the risks of diabetes onset and progression. Am J Med 2010;123:1001-6.
19. Clark DO, Von KM, Saunders K, et al. A chronic disease score with empirically derived weights. Med Care 1995;33:783-95.

20. Kalbfleisch JD, Prentice RL. The Statistical Analysis of Failure Time Data. New York: John Wiley \& Sons, Ltd, 1980.

21. Gonzalez AV, Suissa S, Ernst P. Gender differences in survival following hospitalisation for COPD. Thorax 2011;66:38-42.

22. Roberts CM, Lowe D, Bucknall CE, et al. Clinical audit indicators of outcome following admission to hospital with acute exacerbation of chronic obstructive pulmonary disease. Thorax 2002:57:137-41.

23. Soler-Cataluna JJ, Martinez-Garcia MA, Sanchez LS, et al. Severe exacerbations and BODE index: two independent risk factors for death in male COPD patients. Respir Med 2009:103:692-9.

24. Celli BR, Cote CG, Marin JM, et al. The body-mass index, air ow obstruction dyspnea, and exercise capacity index in chronic obstructive pulmonary disease. $N$ Engl J Med 2004:350:1005-12.

25. Hoogendoorn M, Hoogenveen RT, Rutten-van Molken MP, et al. Case fatality of COPD exacerbations: a meta-analysis and statistical modelling approach. Eur Respir J 2011;37:508-15

26. McGhan R, Radcliff T, Fish R, et al. Predictors of rehospitalization and death after a severe exacerbation of COPD. Chest 2007:132:1748-55.

27. Wilchesky M, Tamblyn RM, Huang A. Validation of diagnostic codes within medica services claims. J Clin Epidemiol 2004;57:131-41.

28. Roberts CM, Stone RA, Buckingham RJ, et al. Acidosis, non-invasive ventilation and mortality in hospitalised COPD exacerbations. Thorax 2011;66:43-8.

29. Niewoehner DE, Erbland ML, Deupree RH, et al. Effect of systemic glucocorticoids on exacerbations of chronic obstructive pulmonary disease. Department of Veterans Affairs Cooperative Study Group. N Engl J Med 1999;340:1941-7.

30. Aaron SD, Vandemheen $\mathrm{KL}$, Hebert $\mathrm{P}$, et al. Outpatient oral prednisone after emergency treatment of chronic obstructive pulmonary disease. $N$ Engl J Med 2003;348:2618-25.

31. Quon BS, Gan W0, Sin DD. Contemporary management of acute exacerbations of COPD: a systematic review and metaanalysis. Chest 2008;133:756-66.

32. Naylor MD. Transitional care: a critical dimension of the home healthcare quality agenda. J Healthc Qual 2006:28:48-54.

33. Calverley PM, Anderson JA, Celli B, et al. Salmeterol and uticasone propionate and survival in chronic obstructive pulmonary disease. $\mathrm{N} \mathrm{Engl} \mathrm{J} \mathrm{Med}$ 2007:356:775-89.

34. Tashkin DP, Celli B, Senn S, et al. A 4-year trial of tiotropium in chronic obstructive pulmonary disease. N Engl J Med 2008;359:1543-54.

35. Vogelmeier C, Hederer B, Glaab T, et al. Tiotropium versus salmeterol for the prevention of exacerbations of COPD. N Engl J Med 2011;364:1093-103.

36. Effing T, Monninkhof EM, van der Valk PD, et al. Self-management education for patients with chronic obstructive pulmonary disease. Cochrane Database Syst Rev 2007; (4):CD002990.

37. Fitzgerald JM. Targeting lung attacks. Thorax 2011;66:365-6. 